\title{
Book Reviews - Livres nouveaux - Buchbesprechungen
}

M. B. Talbot, E. H. Sobel, J. W. McArthur and /. jD. Crawford: Functional Endo crinology. From Birth Through Adolescence. Harvard University Press, Cambridge, Mass. 1952. 638 pages, 220 figures, 59 tables.

In their preface, the authors state that this book is written for medical men "who seek practical information concerning (a) the actions of endocrine systems in health and ordinary diseases and (b) the management of endocrinopathies as they occur in young people”. In nine comprehensive chapters the book deals with the thyroid, parathyroids, adrenal cortices and meduilae, ovaries, testes, anterior and posterior pituitary, and the pancreatic islets, respectively. Basic and clinical considerations are thoroughly treated and most emphasis is put on the homeostatic functions of the single glands and the endocrine system. The great role, which the mutual relations among the endocrine glands play, is also clearly emphasized. The physiologic information is exhaustive, and most readable. The descriptions of the different clinical states are clear and instructive and always based on a careful analysis and estimation of the physiological facts. The thera peutic suggestions are sound and practical. The illustrations are well selected and the numerous diagrams and graphs particularly useful. This book is a basic con tribution to this important subject. The authors express their appreciation to the Commonwealth Fund of New York, "whose generous aid made it possible to work together as a team both in writing this book and in accumulating much of the information presented herein”. I am sure that all the numerous readers readily endorse this appreciation. Paul Kallós, Helsingborg. 